\title{
TU/e emonownen

\section{Functional peptide presentation on different hydrogen bonding biomaterials using supramolecular additives}

\section{Citation for published version (APA):}

van Gaal, R. C., Buskermolen, A. B. C., Ippel, B. D., Fransen, P-P. K. H., Zaccaria, S., Bouten, C. V. C., \& Dankers, P. Y. W. (2019). Functional peptide presentation on different hydrogen bonding biomaterials using supramolecular additives. Biomaterials, 224, [119466]. https://doi.org/10.1016/j.biomaterials.2019.119466

\section{Document license:}

TAVERNE

DOI:

10.1016/j.biomaterials.2019.119466

Document status and date:

Published: 01/12/2019

\section{Document Version:}

Publisher's PDF, also known as Version of Record (includes final page, issue and volume numbers)

\section{Please check the document version of this publication:}

- A submitted manuscript is the version of the article upon submission and before peer-review. There can be important differences between the submitted version and the official published version of record. People interested in the research are advised to contact the author for the final version of the publication, or visit the $\mathrm{DOI}$ to the publisher's website.

- The final author version and the galley proof are versions of the publication after peer review.

- The final published version features the final layout of the paper including the volume, issue and page numbers.

Link to publication

\section{General rights}

Copyright and moral rights for the publications made accessible in the public portal are retained by the authors and/or other copyright owners and it is a condition of accessing publications that users recognise and abide by the legal requirements associated with these rights.

- Users may download and print one copy of any publication from the public portal for the purpose of private study or research.

- You may not further distribute the material or use it for any profit-making activity or commercial gain

- You may freely distribute the URL identifying the publication in the public portal.

If the publication is distributed under the terms of Article 25fa of the Dutch Copyright Act, indicated by the "Taverne" license above, please follow below link for the End User Agreement:

www.tue.nl/taverne

Take down policy

If you believe that this document breaches copyright please contact us at:

openaccess@tue.nl

providing details and we will investigate your claim. 


\title{
Functional peptide presentation on different hydrogen bonding biomaterials using supramolecular additives
}

\author{
Ronald C. van Gaal ${ }^{\mathrm{a}, \mathrm{b}}$, Antonetta B.C. Buskermolen ${ }^{\mathrm{a}, \mathrm{b}}$, Bastiaan D. Ippel ${ }^{\mathrm{a}, \mathrm{b}}$, \\ Peter-Paul K.H. Fransen ${ }^{\mathrm{b}, \mathrm{c}}$, Sabrina Zaccaria ${ }^{\mathrm{b}, \mathrm{c}}$, Carlijn V.C. Bouten ${ }^{\mathrm{a}, \mathrm{b}}$, Patricia Y.W. Dankers ${ }^{\mathrm{a}, \mathrm{b}, \mathrm{c}, *}$ \\ ${ }^{a}$ Laboratory for Cell and Tissue Engineering, PO Box 513, 5600, MB, Eindhoven, the Netherlands \\ ${ }^{\mathrm{b}}$ Institute for Complex Molecular Systems, PO Box 513, 5600, MB, Eindhoven, the Netherlands \\ ${ }^{c}$ Laboratory of Chemical Biology, Eindhoven University of Technology, PO Box 513, 5600, MB, Eindhoven, the Netherlands
}

\section{A R T I C L E IN F O}

\section{Keywords:}

Supramolecular biomaterials

Bisurea

Ureido-pyrimidinone

Peptide presentation

Focal adhesions

RGD

\begin{abstract}
A B S T R A C T
Supramolecular biomaterials based on hydrogen bonding units can be conveniently functionalized in a mix-andmatch approach using supramolecular additives. The presentation of bioactive additives has been sparsely investigated in supramolecular-based elastomeric biomaterials. Here it was investigated how cell adhesive peptides are presented and affect the surface in supramolecular biomaterials based either on ureido-pyrimidinone (UPy) or bisurea (BU) moieties. Polycaprolactone modified with UPy or BU moieties served as the base material. RGD or cyclic (c)RGD were conjugated to complementary supramolecular motifs, and were mixed with the corresponding base materials as supramolecular additives. Biomaterial surface morphology changed upon bioactivation, resulting in the formation of random aggregates on UPy-based materials, and fibrous aggregates on BU-materials. Moreover, peptide type affected aggregation morphology, in which RGD led to larger cluster formation than cRGD. Increased cRGD concentrations led to reduced focal adhesion size and cell migration velocity, and increased focal adhesion numbers in both systems, yet most prominent on functionalized BUbiomaterials. In conclusion, both systems exhibited distinct peptide presenting properties, of which the BUsystem most strongly affected cellular adhesive behavior on the biomaterial. This research provided deeper insights in the differences between supramolecular elastomeric platforms, and the level of peptide introduction for biomaterial applications.
\end{abstract}

\section{Introduction}

New functional biomaterials are paving the way for medical treatment strategies [1-3]. At the fundament of novel biomaterials development lays inspiration acquired from the natural extracellular matrix (ECM) $[1,3,4]$. The ECM varies in composition between tissues and within, and is capable of directing cell function and phenotype $[5,6]$. The effects on cell behavior arise from a complex interplay between mechanical and chemical properties, topology, and the dynamic behavior of all ECM constituents [6,7].

Integration of this diverse set of cues is initiated by integrin binding to specific peptide sequences in the ECM. This resulting integrin activation sequentially recruits intracellular focal adhesion (FA) proteins, such as focal adhesion kinase (FAK) and vinculin. The formed FA complexes link to the actin cytoskeleton thereby allowing the interpretation of mechanical signals by the cell $[8,9]$. Biomaterials are frequently surface functionalized with ECM proteins or ECM mimicking peptides, such as the fibronectin derived RGD, to mimic the chemical signaling properties of the ECM and thereby enhance cell engraftment [10-14]. Polymers often require several chemical modification to finally introduce bioactive peptides, but biomaterials which can be bioactivated in one step are favored in terms of ease $[15,16]$.

Supramolecular biomaterials present modular properties, which makes them eminently suitable for complex biomaterial design [17-21]. Their properties originate from specific and directed dynamic non-covalent interactions between supramolecular motifs. Introduction of bioactive peptides or other functional additives conjugated with a specific supramolecular motif allows for modular integration into supramolecular base materials during material formulation [17,22-26]. This permits the formation of a vast library of polymeric materials with bioactive properties and functions. The bulk of supramolecular research is predominantly focused on co-assembly in aqueous environments, while assembly for solid elastomeric supramolecular biomaterials is less well studied [27-29].

\footnotetext{
* Corresponding author. Laboratory for Cell and Tissue Engineering, PO Box 513, 5600, MB, Eindhoven, the Netherlands.

E-mail address: p.y.w.dankers@tue.nl (P.Y.W. Dankers).
} 
Research in our group concentrates on supramolecular biomaterials based on hydrogen bonding ureido-pyrimidinone (UPy) or bisurea (BU) functionalities for several biomedical applications, such the bio-artificial kidney $[4,17,22,30]$. Both supramolecular systems have the ability to self-assemble into nano-fibrous structures, however they have distinct assembly modes. UPy-moieties dimerize through quadruple hydrogen-bonding. The dimers are able to form fibrous structures through $\pi-\pi$ interactions, promoted by additional urea hydrogen bonding separated by a short alkyl spacer from the UPy group [31-33]. Three of the assembled UPy-stacks are postulated to form fibrous structures through lateral assembly [34]. Two common approaches are followed in the modification of short pre-polymers with UPy-moieties. Either the UPy-units are present in a polymer backbone forming a segmented copolymer, or are telechelically coupled to pre-polymers [34-38]. Both present the characteristic fibrous structures as hard phase in a soft matrix. The telechelically modified UPy-polymers show improved longitudinal fiber assembly and ordering [34,36]. Co-assembly of UPypolymers and UPy-based additives has been investigated in order to introduce various functions such as anti-fouling, post-modification, celladhesiveness and heparin binding properties [17,30,35,36,39]. Due to differences in the applied UPy-polymer and in UPy-additive function and design, no systematic, detailed study has been performed on additive presentation.

In the BU-system, BU-groups arrange via bifurcated hydrogenbonding into stacks, in which the spacer between both urea groups determines the assembly. Three to six stacks further assemble laterally into fibrous structures [23,24,40,41]. Elastomeric BU-based polymers are mainly designed as segmented co-polymers where the polymer backbone is modified with BU-units in segments [4,23]. BU-based polymers have been modified with non-bioactive additives, but peptide additives have not been explored [42-44]. A recent study by Ippel et al. showed the importance of BU-additive design for material functionalization to produce anti-fouling surfaces [44].

Although the UPy and the BU system show similarities in fiber formation, subtle nano-level changes can affect the desired cellular response to supramolecular biomaterials [45]. To assess the effect of such changes a deeper understanding of potential differences in peptide additive presentation between both systems is required. In this study, short polycaprolactone (PCL) pre-polymers modified with supramolecular motifs have been employed, either telechelically with UPy-units (PCLdiUPy), or segmented via BU-moieties (PCL-BU). Linear RGD and cyclic RGD (cRGD) were conjugated to the supramolecular moieties (UPy-RGD, UPy-cRGD, BU-RGD, and BU-cRGD) and added in different concentrations to the complementary supramolecular PCL (Fig. 1). In order to elucidate the delicate balance of the supramolecular peptide incorporation into the supramolecular polymers after assembly, thorough surface analysis using atomic force microscopy (AFM) and water contact angle is performed. This is combined with quantitative analysis of cell-material interactions such as FA properties and cell migration.

\section{Results and discussion}

\subsection{Synthesis of supramolecular additives}

The UPy-additive design entails a UPy- $\mathrm{C}_{6}$-Urea- $\mathrm{C}_{6}$-oligo(ethylene glycol) (OEG) $)_{6}-\mathrm{R}$, where $\mathrm{R}$ can be a variety of functional groups, the design has been shown to effectively present peptides and small molecules at the surface $[36,39]$. The syntheses of the UPy-RGD and UPycRGD have been previously reported by de Feijter et al. [46] The BU additive design was adapted from previously reported designs (Schemes $\mathrm{S} 1$ and S2) [44]. The employed design entails $\mathrm{C}_{6}$-Urea- $\mathrm{C}_{4}$-Urea- $\mathrm{C}_{12^{-}}$ $(\mathrm{OEG})_{12}-\mathrm{R}$. A dodecyl spacer was selected for the additive to allow for selective BU hydrogen bonding without urethane interference. In order to balance the amphiphilic properties, the dodecyl spacer was followed by a 12-mer OEG. Successful synthesis of BU-RGD and BU-cRGD was confirmed by liquid chromatography-mass spectrometry (LC-MS; Figs.
S1 and S2).

\subsection{Distinct differences in additive presentation between both supramolecular systems}

The incorporation of peptide additives into hard phase fibers was first investigated through AFM analysis. Both pristine PCLdiUPy and PCL-BU presented characteristic hard phase fiber formation clearly visible AFM phase images (Fig. 2A) [23,37]. A fiber thickness of $8.9 \pm 0.4 \mathrm{~nm}$ was observed for UPy-fibers and $6.9 \pm 0.2 \mathrm{~nm}$ thickness for BU based fibers. The nano-scale morphology of the biomaterials surface changed upon bioactivation, resulting in the appearance of random aggregates on UPy-based materials, and fibrous aggregates on BU-materials (Fig. 2A). UPy-RGD addition gave rise to small punctuated and elongated aggregations which formed larger clusters without a distinct shape as the concentration was increased. UPy-cRGD formed punctuated clusters on the surface and the number of such clusters increased as the concentration increased. The height of surface aggregations did not to exceed the general roughness of the UPy-polymer film (Fig. S4). BU-RGD formed fibrous clusters which increased in size as the concentration increased. In comparison, BU-cRGD formed disorganized fibrous clusters which appear to cover the complete surface when the concentration is increased (Fig. 2A). The height range of the aggregations was between 12.8 and $21.5 \mathrm{~nm}$ in the BU-system (Fig. S4). It can most likely be omitted that topology induced by BU surface aggregations will affect cell behavior, as it is below the $35 \mathrm{~nm}$ height threshold which cells are proposed to be able to sense [47]. It is assumed that the dynamics of the supramolecular additives are considerably reduced in elastomeric materials, thereby indicating that the observed aggregates remain relatively stable over time [45].

Further surface characterization revealed a water contact angle (WCA), a measure for hydrophobicity, of $74.6 \pm 0.7^{\circ}$ on pristine PCLdiUPy. The addition of UPy-RGD reduced hydrophobicity to $71.0 \pm 0.3^{\circ}(1 \mathrm{~mol} \%)$ and $58.3 \pm 3.8^{\circ}$ ( $4 \mathrm{~mol} \%$ ) as concentration was increased in PCLdiUPy films. Incorporation of UPy-cRGD resulted in a markedly smaller decrease reaching $66.9 \pm 0.4^{\circ}$ (4 mol\%) after PCLdiUPy functionalization (Fig. 2B). Pristine PCL-BU had a surface hydrophobicity comparable to pristine PCLdiUPy, of $74.6 \pm 2.1^{\circ}$. Biofunctionalization with BU-RGD drastically decreased surface hydrophobicity to $30.0 \pm 1.1^{\circ}$ ( $4 \mathrm{~mol} \%$ ) compared to pristine PCL-BU. The addition of BU-cRGD resulted in a more gradual decrease ending in a WCA of $33.3 \pm 0.6^{\circ}(4 \mathrm{~mol} \%)$ as the concentration was increased in PCL-BU. Taken together, AFM and water contact angle measurements showed that the additive presentation was enhanced on PCL-BU surfaces compared to PCLdiUPy.

Surface alterations after incorporation of UPy- and BU-additives have been extensively studied in literature [36,39,42-44]. However, additive design and type, or the employed supramolecular polymer were often varied, therefore a systematic comparison has not been performed in the past. A UPy-tetrazine and UPy-heparin binding peptide with the $\mathrm{UPy}-\mathrm{OEG}_{6}$-additive design gave rise to either plaque formation or phase separation at the biomaterial surface, different from the aggregation observed in this study for UPy-RGD and UPy-cRGD $[36,39]$. No previous investigations have been performed for BU-peptide additive surface presentation. BU-pyrene additives have been shown to form fibrous aggregates in higher concentration on material surfaces reminiscent of the fibrous aggregations found for BU-RGD and BU-cRGD [43]. However, this BU-pyrene additive design has differences in alkyl-spacer between urea, and linker size compared with the currently employed BU-peptide additive. Recently, PCL-BU was functionalized with a BU-OEG 12 -methoxy additive to create non-cell adhesive surfaces [44]. The molecular design of the additive was highly similar compared to the BU additive employed in this study, the only difference was the OEG end-group. AFM analysis of the BU-OEG $12^{-}$ methoxy functionalized PCL-BU revealed sparse small aggregations at the surface. Moreover, differences here observed in aggregations 

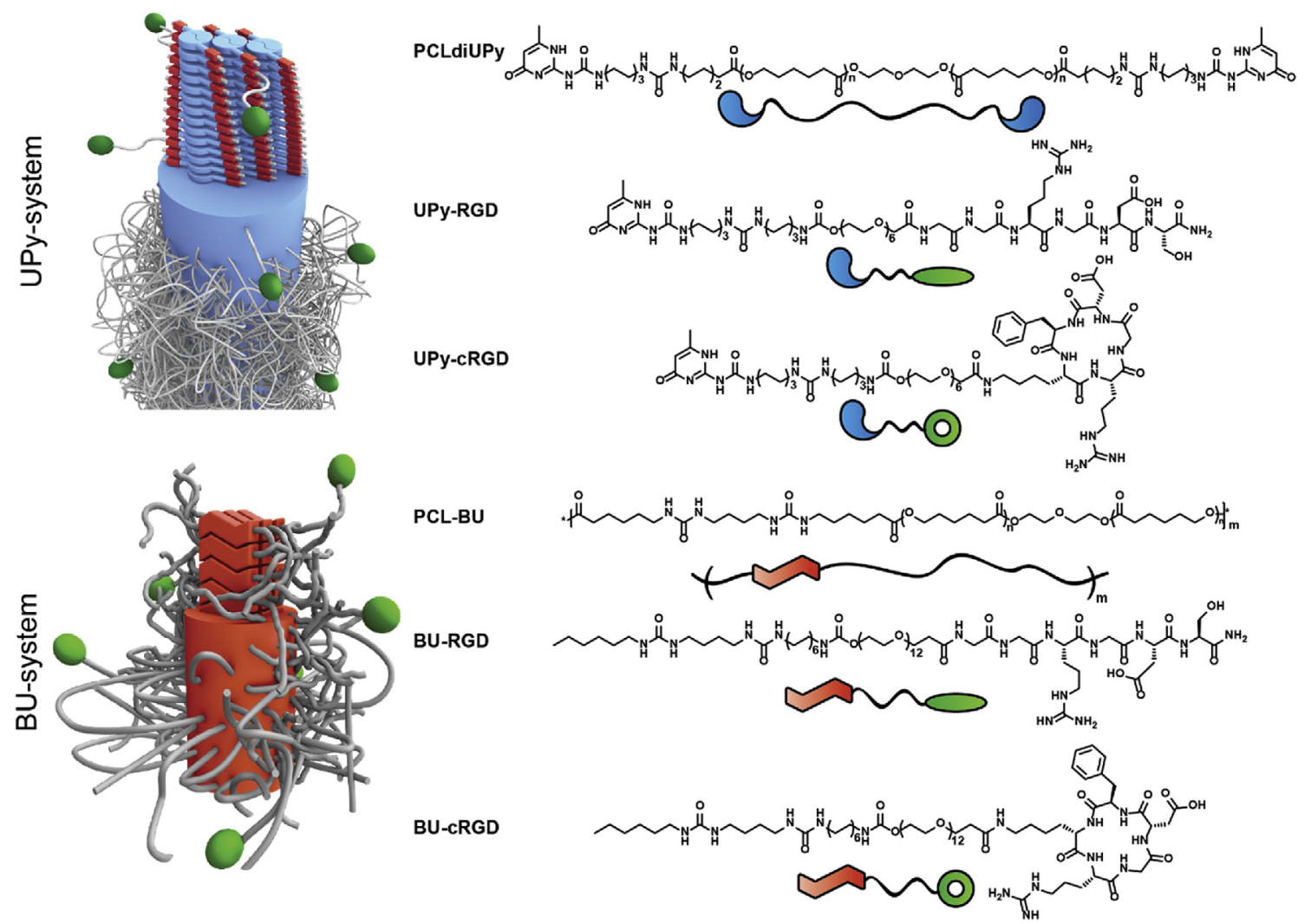

Fig. 1. Schematic representation of the supramolecular systems. Left. Schematic representation of ureido-pyrimidinone (UPy; blue) and bisurea (BU; red) fibers functionalized with an additive (green). Right. Chemical structures and schematic representations of employed supramolecular polymers and additives. (For interpretation of the references to colour in this figure legend, the reader is referred to the Web version of this article.)

between cRGD and RGD indicate that the peptide itself influences the assembly process at the surface of both supramolecular systems. Summarized, the employed supramolecular system and the functional group of a supramolecular additives are important for the additive presentation mode at the nano-scale.

\subsection{Focal adhesion properties and cell velocity indicate functional peptide presentation}

Functional peptide presentation in both supramolecular systems was primarily investigated via quantitative analysis of the FAs, which are the primary protein complexes involved in cell-biomaterial adhesion. FAs have been shown to increase in number and decrease in size as the concentration of accessible surface cRGD is increased. A similar response can be observed for RGD functionalization, but is less pronounced [12]. The variation in FA response originates from the different integrin dimers required for both RGD sequences, they present different binding affinities and differences in FA nucleation potential and growth $[12,16]$. It was assumed that the surface additive aggregates remain stable in an aqueous environment [44].

Large elongated FAs were observed on both pristine PCLdiUPy and PCL-BU films displaying $5.5 \pm 0.3$ and $6.6 \pm 0.6$ FAs per $100 \mu \mathrm{m}^{2}$ cell area, respectively (Fig. 3A and B). Functionalization of PCLdiUPy with both UPy-RGD and UPy-cRGD resulted in non-significant changes in FA numbers compared to pristine PCLdiUPy. PCL-BU with the fibrous BURGD aggregates led to a non-significant increase in FA numbers compared to pristine PCL-BU. Introduction of BU-CRGD resulted in a significant concentration dependent increase in FAs compared to pristine PCL-BU, $9.6 \pm 0.8(1 \mathrm{~mol} \% ; \mathrm{p} \leq 0.01)$ and $14.5 \pm 1.4(4 \mathrm{~mol} \%$; $\mathrm{p} \leq 0.001$ ) FAs per $100 \mu \mathrm{m}^{2}$ cell area (Fig. $3 \mathrm{~A}$ and B). The number of FA induced by BU-cRGD functionalized PCL-BU was shown to be significantly higher compared to UPy-cRGD functionalization of PCLdiUPy
( $\mathrm{p} \leq 0.001$ ). Correlating to the aggregate coverage on both materials. Related to the FA density results, non-significant differences were found in cell area after biofunctionalization for both systems (Fig. S5).

Cells cultured on pristine PCLdiUPy presented FAs with a mean size of $1.48 \pm 0.03 \mu \mathrm{m}^{2}$. Introduction of UPy-RGD or UPy-cRGD led to a concentration dependent decrease in size reaching $1.26 \pm 0.02 \mu \mathrm{m}^{2}$ for UPy-RGD ( $4 \mathrm{~mol} \%$ ) and $1.11 \pm 0.01 \mu \mathrm{m}^{2}$ for UPy-cRGD ( $4 \mathrm{~mol} \%$; Fig. $3 \mathrm{~A}$ and $\mathrm{B})$. FAs on PCL-BU adopted a larger size compared to PCLdiUPy, which was $1.62 \pm 0.03 \mu \mathrm{m}^{2}$. BU-RGD addition led to a concentration independent decrease in size compared to pristine PCL$\mathrm{BU}$ resulting in a FA size of $1.10 \pm 0.01 \mu \mathrm{m}^{2}(4 \mathrm{~mol} \%)$. The inclusion of BU-cRGD resulted in a concentration dependent decrease in FA size compared to pristine PCL-BU, reaching $0.77 \pm 0.01 \mu \mathrm{m}^{2}$ ( $4 \mathrm{~mol} \%$; Fig. 3A and B). Surface aggregates of $4 \mathrm{~mol} \%$ of UPy-cRGD appeared to initiate an equal response as $1 \mathrm{~mol} \% \mathrm{BU}$-cRGD in FA size, while $4 \mathrm{~mol} \%$ BU-cRGD was significantly lower than 4 mol\% UPy-cRGD ( $\mathrm{p} \leq 0.001$ ). It is interesting to note that the size of one $\mathrm{FA}$, i.e, roughly $1 \mu \mathrm{m}^{2}$, corresponds to the area depicted in the AFM images (Fig. 2A).

In response to bioactivation, FAs adopted a more punctuated morphology compared to pristine materials, except for the addition of $1 \mathrm{~mol}$ $\%$ UPy-RGD (Fig. 3B). A round FA morphology can be an indication of a nascent phenotype, as opposed to a more mature phenotype $[8,12]$. Mature FAs can be defined as $\mathrm{pFAK}^{+}$and zyxin ${ }^{+}$, while nascent FAs lack zyxin [8]. Overall, pFAK and zyxin appeared to co-localize in the majority of observed FAs in both the UPy- and BU-system (Figs. S6 and S7). However, slightly more nascent FAs could be observed with the introduction of cRGD in general, i.e., $4 \mathrm{~mol} \%$ of UPy-cRGD, and 1 or $4 \mathrm{~mol} \%$ of BU-cRGD.

All cell-material interaction experiments were performed in cell culture medium supplemented with serum. However, the presence of serum proteins can largely influence FA behavior. Therefore, the adhesion experiment was repeated without serum. It was shown that 
A

Pristine
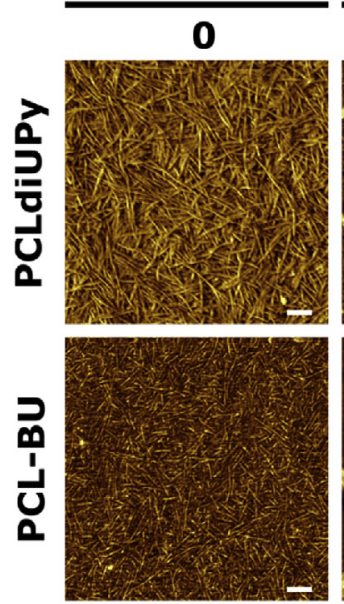

B
RGD
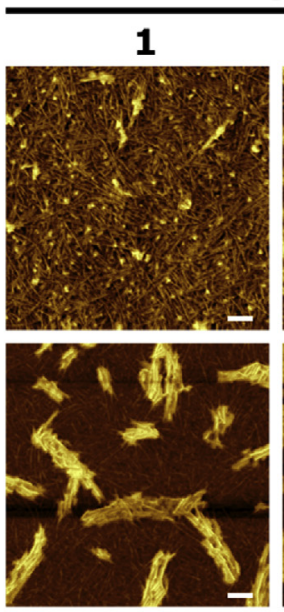

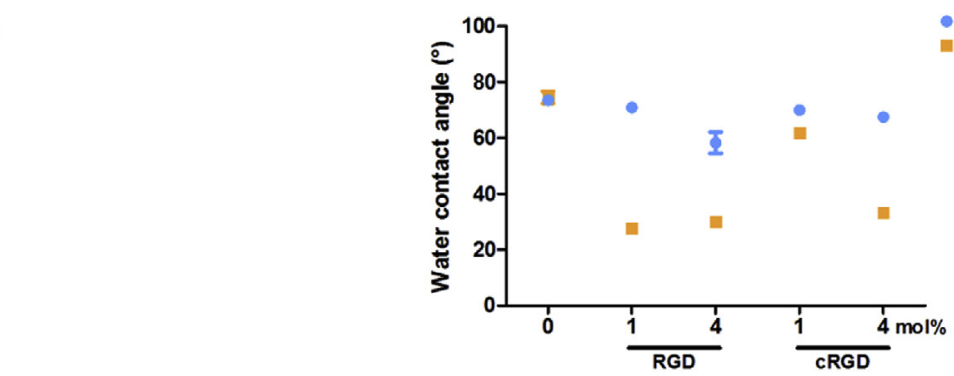

CRGD
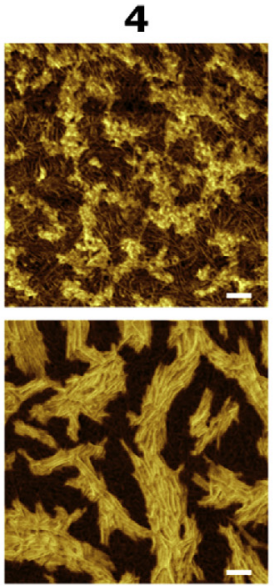

PCLdiUPy

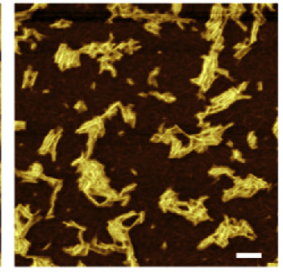

1
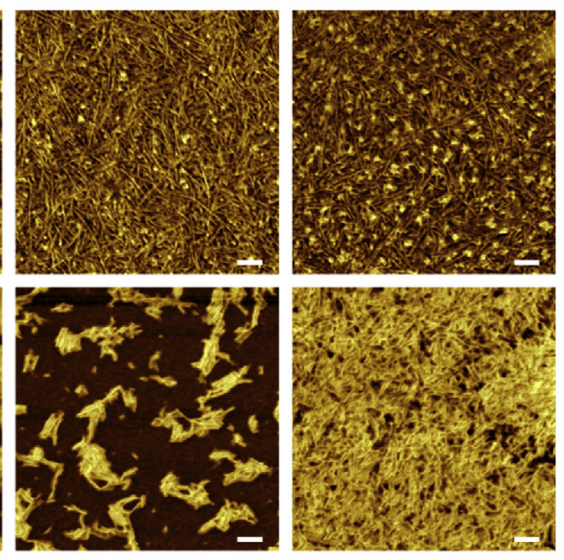

$4 \mathrm{~mol} \%$

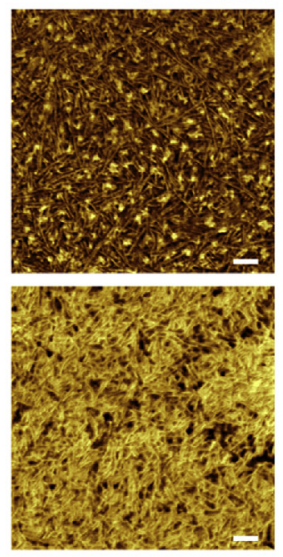

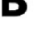

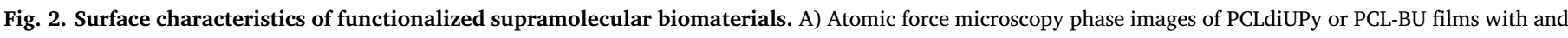

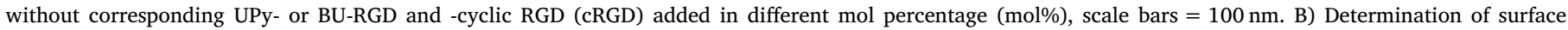
wettability through water contact angle analysis on the material interface. Mean \pm standard error of the mean (SEM) depicted, $\mathrm{n}=3$.

responses observed in FA number and size appeared to be independent of the presence of serum (Fig. S8). These results are in line with recent findings that cells can sense and bind to RGD through a layer of deposited serum proteins within $2 \mathrm{~h}$ post seeding [11]. Additionally, alterations in cell adhesion are likely not the consequence of changes in surface hydrophobicity, as previous research indicated that similar additive designs without adhesion peptides produced anti-fouling surfaces with similar hydrophobicity as presented in this study [44].

FAs are linked by mechanosensitive cytoskeleton to cell-cell contacts. Cell-cell contacts have the potential to alter the forces experienced by the cells and thereby potentially influence the FAs as they adapt to the newly experienced forces $[7,48]$. Therefore it was investigated if cell-cell contacts influenced FAs morphology. However, FAs morphology appeared to be independent of cell-cell contacts as cell clusters appeared to show similar FA properties as single cells (Fig. S9). Additionally, cell clusters showed apparent similar FA morphology at $3 \mathrm{~h}, 24 \mathrm{~h}$ and $72 \mathrm{~h}$ (Fig. S9).

Cells reduce migration speed in response to surfaces functionalized with increasing amounts of RGD or cRGD, as cells are unable to effectively cycle between adherent and non-adherent states due to sheer magnitude in adherent sites [16,49]. Reduction in random migration speed can therefore be considered as an additional measurement of material functionalization. Within the UPy-system only $4 \mathrm{~mol} \%$ UPycRGD was able to reduce cell velocity significantly compared to pristine PCLdiUPy, thereby limiting the distance from the starting position, from $0.75 \pm 0.05 \mu \mathrm{m} / \mathrm{min}$ to $0.54 \pm 0.03 \mu \mathrm{m} / \mathrm{min}$ ( $\mathrm{p} \leq 0.01$; Figs. 4 and S10). Cells migrated at a speed of $0.81 \pm 0.07 \mu \mathrm{m} / \mathrm{min}$ on pristine PCL-BU (Fig. 4). Both BU-RGD and BU-cRGD addition to PCL-BU resulted in significant reductions in cell velocity (Figs. 4 and S10). BURGD surface aggregates induced a concentration independent reduction in migration speed with $0.50 \pm 0.04 \mu \mathrm{m} / \mathrm{min}$ for $4 \mathrm{~mol} \%$ BU-RGD
( $\mathrm{p} \leq 0.001)$. The introduction of BU-cRGD reduced cell velocity in a concentration dependent matter, i.e. $0.54 \pm 0.04 \mu \mathrm{m} / \mathrm{min}(1 \mathrm{~mol} \%$, $\mathrm{p} \leq 0.01)$ and $0.34 \pm 0.02 \mu \mathrm{m} / \mathrm{min}(4 \mathrm{~mol} \%, \mathrm{p} \leq 0.001)$. Interestingly, similar responses were found for FA size, which confirmed previous reports that migration speed is correlated to FA size and not numbers [50].

Taken together, results indicated more numerous and smaller punctuated FAs arose in response to increasing concentrations of cRGD. The addition of RGD only led to smaller punctuated FAs. The response for both RGD as cRGD was most pronounced in the BU-system, indicating more functional peptide presentation. FAs were primarily found to be mature, and independent of serum presence and cell-cell contacts. Additionally the FA behavior was preserved over time. Random migration was most strongly reduced in the BU-system compared to the UPy system. Cellular read-outs completed indications provided by AFM analysis and hydrophobic properties of the material surfaces that the BU-system excels in presenting functional peptide, at least for cRGD, at the surface compared to the UPy-system.

\subsection{Importance of linker length for peptide presentation}

Linker length has been shown to be crucial for bioactive peptide presentation in different supramolecular and traditional biomaterial platforms $[16,18,51-54]$. With respect to this literature the differences found for the UPy- and BU-system can be caused by the length of the OEG linker which is 6 units for the UPy-additives and 12 units for the BU moieties. To investigate whether the length of the OEG influences the peptide presentation, a UPy-additive with an extended OEG linker was synthesized, i.e. UPy-OEG 12 -cRGD (UPy-cRGD*, Scheme S3, Fig. S3).

The addition of the UPy-cRGD* into the PCLdiUPy polymer resulted 


\section{Pristine}

$\mathbf{0}$
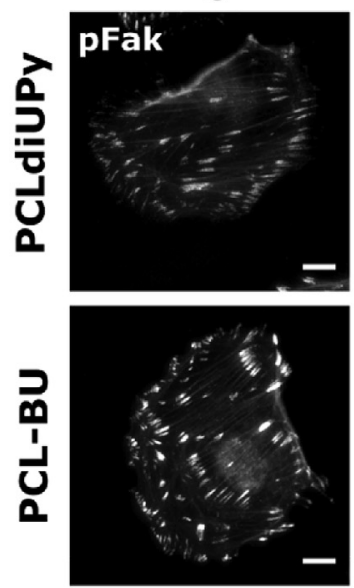

B

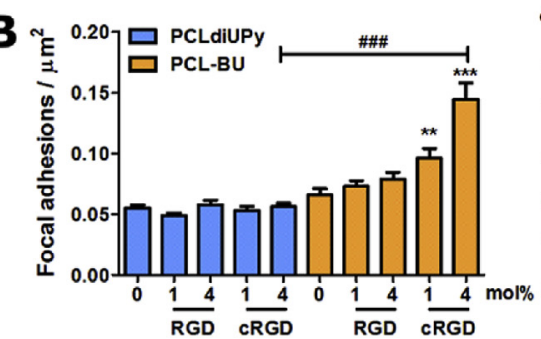

RGD

1
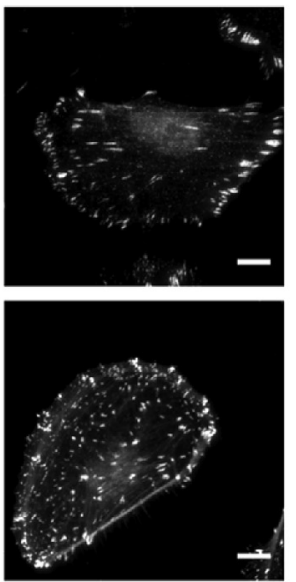

RD

4
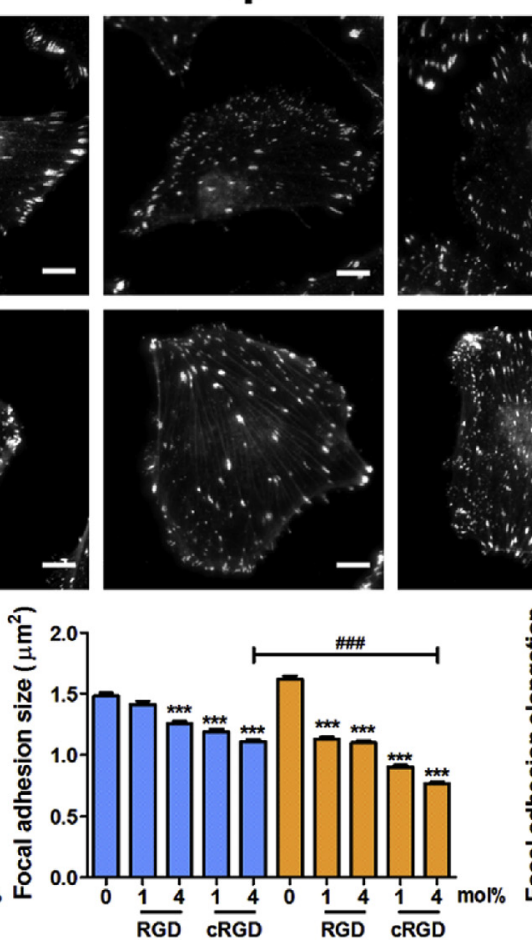

CRGD
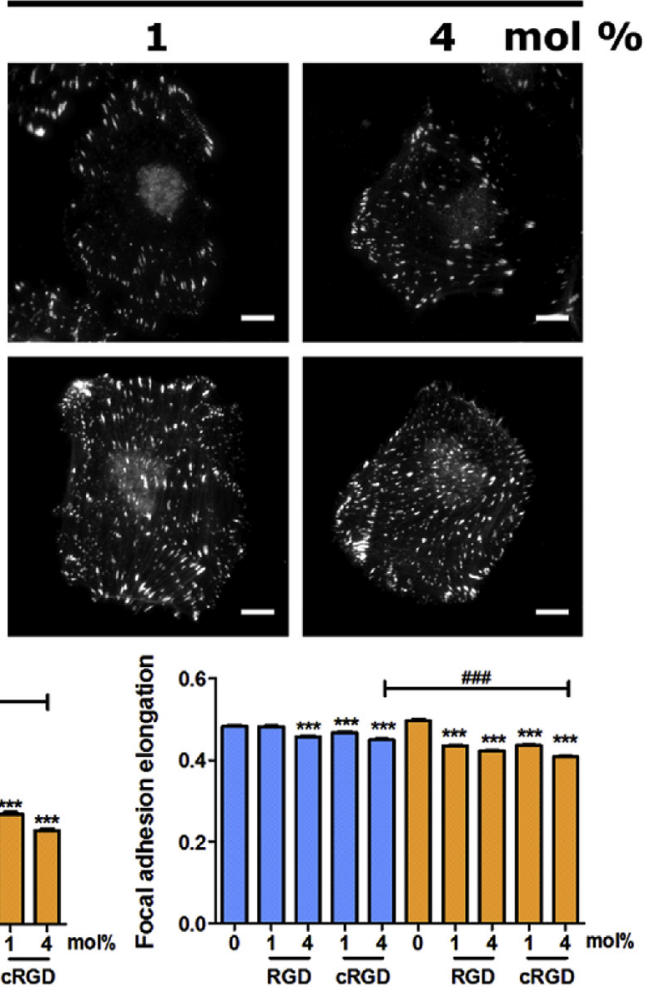

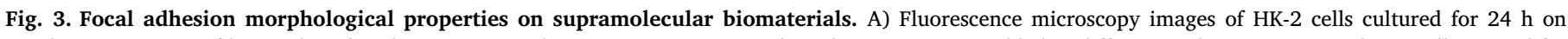

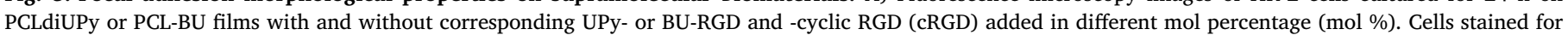

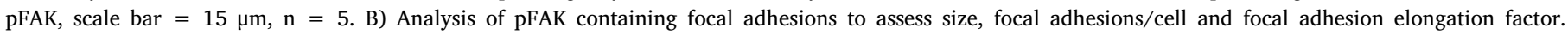
$* * * \mathrm{p} \leq 0.001,{ }^{* *} \mathrm{p} \leq 0.01$, intra supramolecular system compared to pristine; \#\#\#p $\leq 0.001$, inter supramolecular systems.

in similar aggregates on the surface as observed for UPy-cRGD (Figs. 2A, Fig. 5A, S12). The height of the aggregations did not exceed the general roughness of the material (Fig. S13). The AFM images indicate that more surface is covered when the UPy-cRGD* concentration is increased. This exceeds coverage found for UPy-cRGD. Comparison between UPy-cRGD* and BU-cRGD indicated more aggregate coverage at the surface of the BU-system. Hydrophobicity decreased as more UPy-cRGD* was added to PCLdiUPy (Fig. 5A). Interestingly, the WCAs values observed for UPy-cRGD* were between those observed of UPycRGD and BU-cRGD. Combined, AFM and hydrophobicity measurements indicated that cRGD presentation is enhanced through spacer extension.

Addition of UPy-cRGD* to PCLdiUPy resulted in cellular responses that more closely resembled the response on BU-cRGD functionalized PCL-BU than UPy-cRGD in PCLdiUPy (Figs. 5A and S14). More FAs were found on UPy-cRGD* functionalized compared to pristine materials ( $4 \mathrm{~mol} \%, \mathrm{p} \leq$ 0.001; Figs. 5B and S14). Nonetheless, UPy-cRGD* functionalization was unable to provoke similar numbers of FAs as BUcRGD addition did ( $\# \mathrm{p} \leq 0.05)$. An upward trend in cell area could be observed after bioactivation, although it was found to be non-significant (Fig. S15). FA size and elongation followed similar response as $4 \mathrm{~mol} \%$ BU-cRGD with no significant differences between both supramolecular systems (Fig. 5B). Also, using this additive, the absence of serum appeared to induce similar FA responses as in the presence of serum (Fig. S16). Cell migration was more strongly reduced with the UPy-cRGD* compared to UPy-cRGD, and no significant difference in migration speed was found between UPy-cRGD* and BU-cRGD (Figs. 5C and S17).

Collectively, these results indicated that longer linker length improved functional cRGD availability at the biomaterial surface within the UPy-system. UPy-cRGD* was able to elicit a similar response in FA size, FA elongation and cell migration as BU-cRGD. However, AFM, surface hydrophobicity, and FA numbers indicated that cRGD presentation is still superior in the BU-system.

Additive linker length can only partly explain the difference in presentation found between both supramolecular systems. It remains speculative where the difference in peptide presentation between supramolecular systems originates from. Peptide additive presentation in the BU-system is likely favored due to differences in the nanoscale assembly, or could originate from components properties such as surface free energy, or substrate affinity [55].

\section{Conclusion}

Distinct differences are found in the presentation of peptides between BU- and UPy-based supramolecular elastomeric biomaterials, although the two classes of supramolecular biomaterials show comparable assemblies. In addition, the employed peptide influences the nanoscale presentation independent of the employed supramolecular material. Cellular studies indicate that the BU-system more effectively presents functional peptides at the biomaterial surface than the UPybased system. This research provides insights in understanding the difference between supramolecular systems, how changes in chemistry can influence the delicate balance of presentation, and the level of peptide introduction for biomaterial applications. 


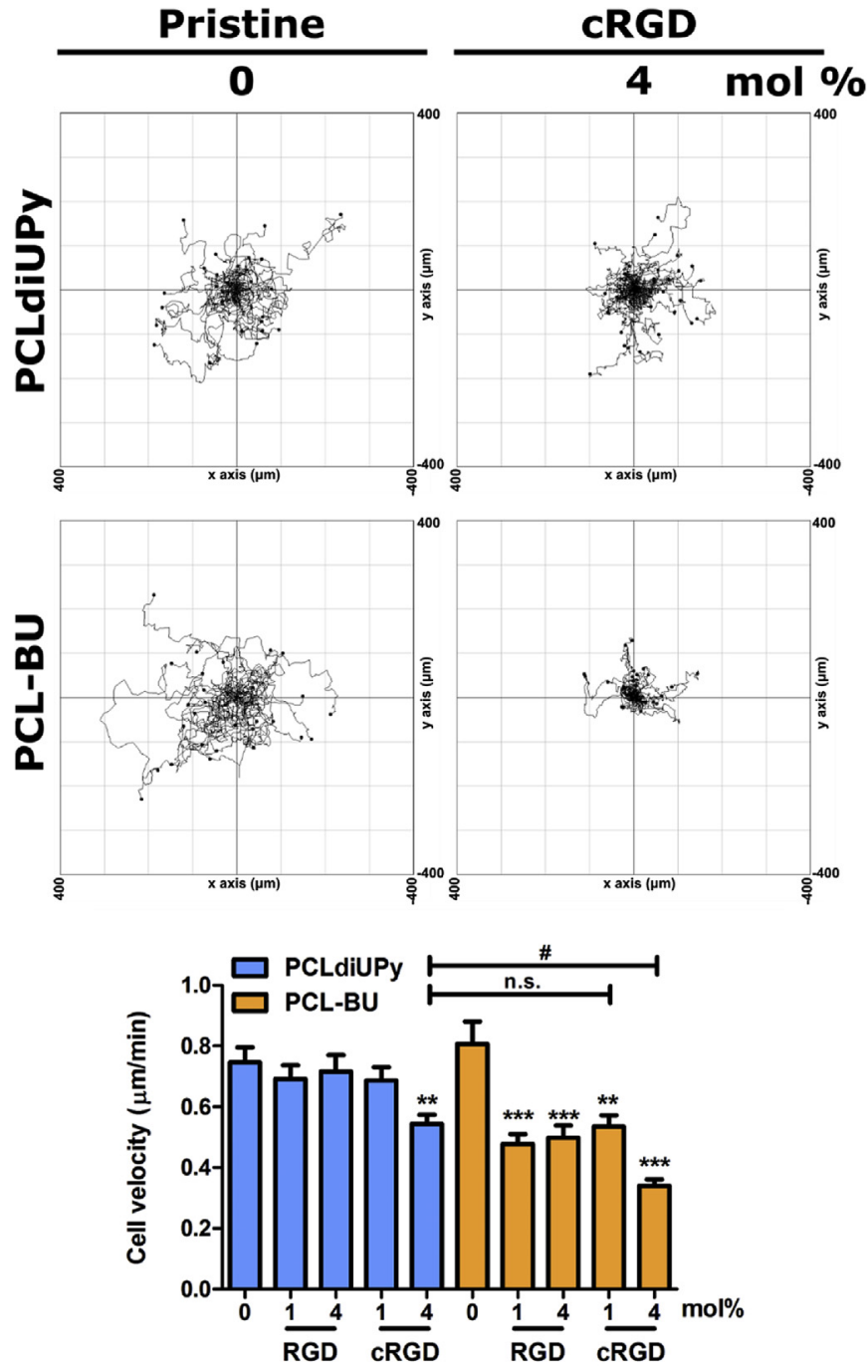

Fig. 4. Cell trajectories and velocity on the supramolecular biomaterials. HK-2 cell velocity on PCLdiUPy and PCL-BU biomaterials with varying levels of (cyclic) cRGD and linear RGD functionalization on corresponding supramolecular motifs. Top part depicts cell trajectory diagrams of cells for $12 \mathrm{~h}$ after $3 \mathrm{~h}$ after initial seeding. Dots represent the final destination of the cell, the line the path taken. Bottom part depicts quantification of the cell velocity. $n=30-40$, $* * * \mathrm{p} \leq 0.001,{ }^{* * \mathrm{p}} \leq 0.01$, intra supramolecular system compared to pristine; $\# \mathrm{p} \leq 0.05$, inter supramolecular systems.

\section{Materials \& methods}

\subsection{Synthesis supramolecular peptides}

Complete peptide sequences for RGD and cRGD were GGRGDS and cyclic(RGDfK) for both supramolecular moieties [58]. UPy-OEG 6 -RGD and -cRGD were synthesized as described previously by Feijter et al. [46]. UPy-OEG $12-\mathrm{COOH}$ synthesis was performed as reported in literature [56]. Conjugation of cRGD to $\mathrm{UPy}-\mathrm{OEG}_{12}-\mathrm{COOH}$ and the synthesis of BU-OEG 12 -RGD and BU-OEG 12 -CRGD is extensively described in the supporting information.

\subsection{Supramolecular polymer film fabrication}

PCLdiUPy $\left(\mathrm{M}_{\mathrm{n}}=2.8 \mathrm{~kg} / \mathrm{mol}\right.$; SyMO-Chem, The Netherlands $)$ and PCL-BU $\left(M_{n}=2.7 \mathrm{~kg} / \mathrm{mol}\right.$; per segmented unit; SyMO-Chem) were dissolved at $20 \mathrm{mg} / \mathrm{mL}$ in 1,1,1,3,3,3-Hexafluoro-2-propanol (Fluorochem, UK). UPy-OEG ${ }_{6}-\mathrm{RGD}$, UPy-OEG 6 -cRGD, or $\mathrm{UPy}-\mathrm{OEG}_{12^{-}}$
cRGD were added at a concentration of 0,1 or $4 \mathrm{~mol} \%$ to the PCLdiUPy solution, taking into account the weight of the entire polymer. BU$\mathrm{OEG}_{12}$-RGD or BU-OEG $12^{-\mathrm{CRGD}}$ were added at 0,1 or $4 \mathrm{~mol} \%$ to the PCL-BU solution, here mol\% was determined by the weight per segmented unit. Clear homogeneously dispersed polymer films were fabricated by casting a $45 \mu \mathrm{L}$ drop of polymer solution on a $14 \mathrm{~mm} \emptyset$ glass coverslips (VWR, USA). The solvent was evaporated at RT between 30 and $40 \%$ humidity. The resulting films were placed overnight under vacuum to remove residual solvent. The polymer covered coverslips were mounted in custom holders to prevent film detachment during cell culture. The holders consist out of a 12 well Transwell insert (Corning, USA) without membrane and a custom ring which can be clamped on the insert.

\subsection{Surface morphology}

\subsubsection{Atomic force microscopy}

A Digital Instruments Multimode Nanoscope IIIa, operating in the tapping mode regime, was used to record phase and height images of solution-cast films at room temperature with silicon cantilever tips (PPP-NCHR, NanoSensors ${ }^{\mathrm{tm}}$, 204-497 kHz, 10-130 N/m). Images were processed using Gwyddion software (version 2.43). Fiber thickness was measured from phase images in ImageJ (version $1.48 \mathrm{v}$, National Institutes of Health, USA).

\subsubsection{Determination hydrophobicity polymer films}

Hydrophobicity of polymer films was determined with contact angle system OCA and SCA 202 v4.1.13 build 1020 software (Dataphysics Instruments, Germany). A $4 \mu \mathrm{L}$ water droplet was deposited on the polymer surface, images were taken at $30 \mathrm{~s}$ after droplet deposition and contact angles were determined. Two droplets per sample were deposited over 3 replicates.

\subsection{Cell culture}

Human kidney 2 cells (HK-2; ATCC, Germany) were cultured in Dulbecco's Modified Eagle Medium (DMEM; 41966, Gibco, UK), supplemented with $10 \%$ v/v fetal bovine serum (FBS; Greiner Bio-one, The Netherlands) and $1 \% \mathrm{v} / \mathrm{v}$ penicillin and streptomycin (Invitrogen, USA) under standard culturing conditions at $37{ }^{\circ} \mathrm{C}$ and $5 \% \mathrm{CO}_{2}$. Cells were seeded on the polymer surfaces at a density of $10 * 10^{3}$ cells $/ \mathrm{cm}^{2}$. Experiments were replicated in quadruplicate. In serum free experiments the medium was completed without FBS and cells were washed and resuspended in serum free medium before cell seeding. Serum free experiments were replicated three times.

\subsection{Fluorescence staining}

Cells were fixed with $3.7 \% \mathrm{v} / \mathrm{v}$ formaldehyde solution (Merck, USA) plus $0.5 \% \mathrm{v} / \mathrm{v}$ Triton X-100 (Merck) in phosphate buffered saline (PBS; Sigma-Aldrich) for $10 \mathrm{~min}$ at room temperature (RT) after $3 \mathrm{~h}, 24 \mathrm{~h}$ or $72 \mathrm{~h}$ post seeding. Samples were subsequently washed with PBS and blocked with $5 \% \mathrm{w} / \mathrm{v}$ BSA (Roche, The Netherlands) in PBS for 20 min at RT to prevent aspecific antibody binding. FA were stained with anti-FAK (pY397; mouse IgG1; BD Bioscience, USA) and anti-zyxin (IgG rabbit; Sigma-Aldrich) for $60 \mathrm{~min}$ in staining buffer ( $2 \% \mathrm{w} / \mathrm{v}$ BSA, $0.05 \%$ Triton X-100 in PBS) at RT. After washing with $0.05 \%$ Triton X100 in PBS samples were incubated with secondary antibodies Goat- $\alpha$ Mouse-Alexa Fluor 555 and Goat- $\alpha$-Rabbit-Alexa Fluor 647 (Molecular Probes, USA) phalloidin-Atto 488 (Sigma-Aldrich) in staining buffer for $45 \mathrm{~min}$ with the last $10 \mathrm{~min}$ 4'-6-diamidino-2-phenylindole (DAPI; $0.1 \mu \mathrm{g} / \mathrm{mL}$; Sigma-Aldrich) added. Samples were finally washed with PBS and mounted with Mowiol (Sigma-Aldrich). FA were imaged with a Zeiss Axiovert $200 \mathrm{M}$ microscope with $63 \times$ magnification and AxioVision software (Zeiss, Germany) for quantification. 


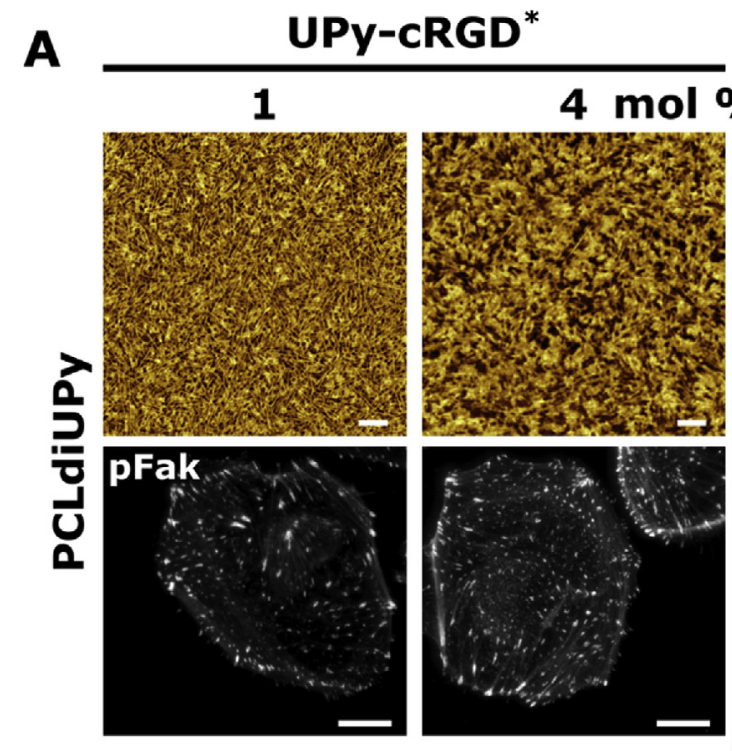

B
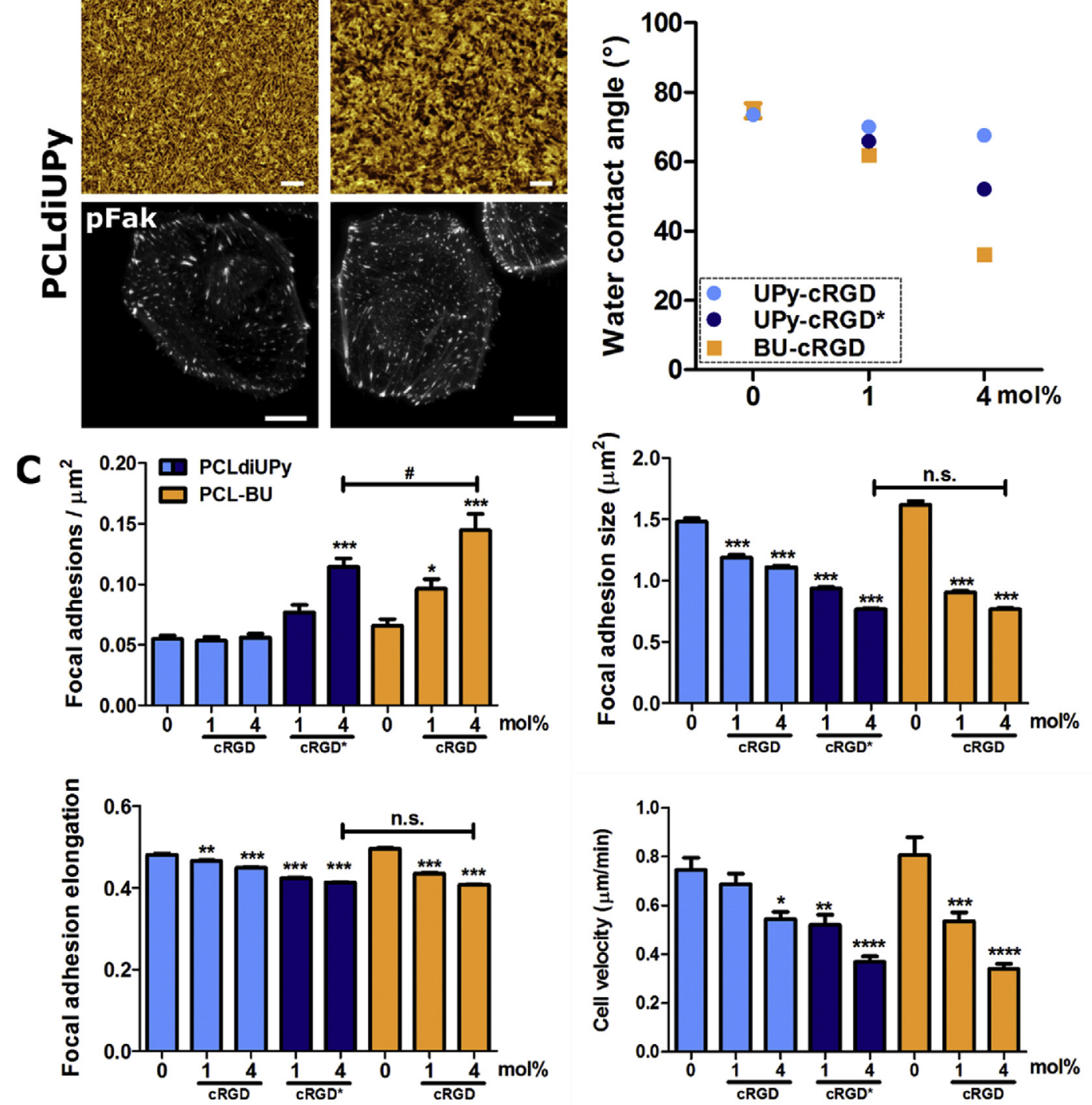

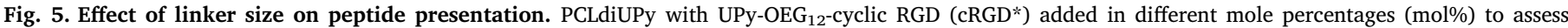

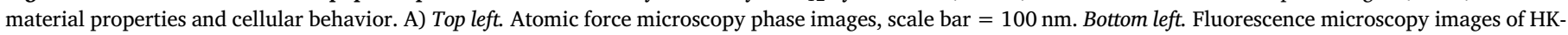

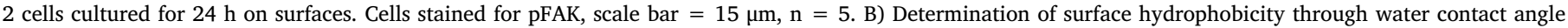

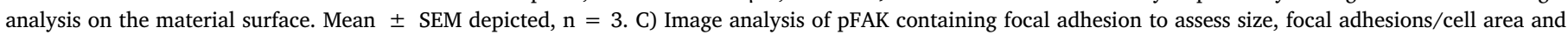

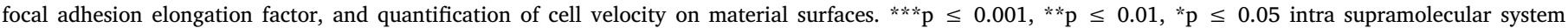

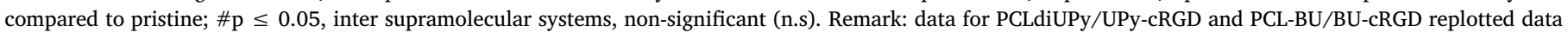
from Figs. 2 and 3 for convenience.

\subsection{Focal adhesion quantification}

Cell area and FA size, elongation and number per cell were determined using a custom-built Mathematica script (version 11.1, Wolfram Research Inc., USA), as previously described by Buskermolen et al. [57]. Single cells were selected in the software for analysis. FAs between $0.1 \mu \mathrm{m}^{2}$ and $11 \mu \mathrm{m}^{2}$ were used for further analysis. Elongation was determined as 1 - (FA length/FA width) ${ }^{-1}$, thereby a perfect circle has an elongation of 0 . Per condition approximately 10-20 single cells were selected and analyzed in each of the four replicates $(n=40-58)$.

\subsection{Migration}

HK-2s were seeded as stated before and were allowed to adhere for $3 \mathrm{~h}$ on polymer surfaces. Cells were imaged at $5 \mathrm{~min}$ intervals for $12 \mathrm{~h}$ with a CytoMate (CytoSMART Technologies B.V., The Netherlands). Images were converted to stacks with ImageJ. Migration paths of 10 random cells were manually tracked in triplicate for each condition ( $\mathrm{n}=30$ ) with MTrackJ (University Medical Center Rotterdam, The Netherlands) and analyzed with Chemotaxis and Migration Tool (version 1.01, ibidi GmbH, Germany), both within ImageJ. 


\subsection{Statistical analysis}

Data regarding FA size and the number of FAs per cell, as well as data on migration velocity of cells were subjected to a one way ANOVA followed by a Bonferroni post-test to compare all conditions with each other. Data $\mathrm{n} \leq 5$ were subjected to a Kruskal-Wallis test with a Dunns post-test in which all conditions were compared. Tests were performed with the use of Prism 5 (GraphPad Software Inc., La Jolla, USA). Probabilities of $\mathrm{p} \leq 0.05$ were considered as significantly different.

\section{Acknowledgements}

This work was financially supported by the European Research Council (FP7/2007-2013) ERC Grant Agreement 308045, the Ministry of Education, Culture and Science, the Netherlands (Gravity program 024.001.03 and 024.003.013), and received funding from the Union's Seventh Framework Program (FP/2007-2013) under Grant Agreement number 310389 (BIP-UPy).

\section{Appendix A. Supplementary data}

Supplementary data to this article can be found online at https:// doi.org/10.1016/j.biomaterials.2019.119466.

\section{References}

[1] N. Gjorevski, N. Sachs, A. Manfrin, S. Giger, M.E. Bragina, P. Ordóñez-Morán, H. Clevers, M.P. Lutolf, Designer matrices for intestinal stem cell and organoid culture, Nature 539 (2016) 560-564, https://doi.org/10.1038/nature20168.

[2] B.A. Badeau, M.P. Comerford, C.K. Arakawa, J.A. Shadish, C.A. DeForest, Engineered modular biomaterial logic gates for environmentally triggered therapeutic delivery, Nat. Chem. 10 (2018) 251-258, https://doi.org/10.1038/nchem. 2917.

[3] X.H. Qin, X. Wang, M. Rottmar, B.J. Nelson, K. Maniura-Weber, Near-infrared lightsensitive polyvinyl alcohol hydrogel photoresist for spatiotemporal control of cellinstructive 3D Microenvironments, Adv. Mater. 30 (2018) 1705564, , https://doi. org/10.1002/adma.201705564.

[4] J. Kluin, H. Talacua, A.I.P.M. Smits, M.Y. Emmert, M.C.P. Brugmans, E.S. Fioretta, P.E. Dijkman, S.H.M. Söntjens, R. Duijvelshoff, S. Dekker, M.W.J.T. Janssen-van den Broek, V. Lintas, A. Vink, S.P. Hoerstrup, H.M. Janssen, P.Y.W. Dankers, F.P.T. Baaijens, C.V.C. Bouten, In situ heart valve tissue engineering using a bior esorbable elastomeric implant - from material design to 12 months follow-up in sheep, Biomaterials 125 (2017) 101-117, https://doi.org/10.1016/j.biomaterials 2017.02.007.

[5] J.H. Miner, Renal basement membrane components, Kidney Int. 56 (1999) 2016-2024, https://doi.org/10.1046/j.1523-1755.1999.00785.x.

[6] C. Frantz, K.M. Stewart, V.M. Weaver, The extracellular matrix at a glance, J. Cell Sci. 123 (2010) 4195-4200, https://doi.org/10.1242/jcs.023820.

[7] M.A. Schwartz, Integrins and extracellular matrix in Mechanotransduction, Cold Spring Harb. Perspect. Biol. 2 (2010), https://doi.org/10.1101/cshperspect. a005066 a005066-a005066.

[8] B. Geiger, K.M. Yamada, Molecular architecture and function of matrix adhesions, Cold Spring Harb. Perspect. Biol. 3 (2011), https://doi.org/10.1101/cshperspect. a005033 a005033-a005033.

[9] E.R. Horton, J.D. Humphries, J. James, M.C. Jones, J.A. Askari, M.J. Humphries, The integrin adhesome network at a glance, J. Cell Sci. 129 (2016) 4159-4163, https://doi.org/10.1242/jcs.192054.

[10] J. Jansen, M. Fedecostante, M.J. Wilmer, J.G. Peters, U.M. Kreuser, P.H. van den Broek, R.A. Mensink, T.J. Boltje, D. Stamatialis, J.F. Wetzels, L.P. van den Heuvel, J.G. Hoenderop, R. Masereeuw, Bioengineered kidney tubules efficiently excrete uremic toxins, Sci. Rep. 6 (2016) 26715, https://doi.org/10.1038/srep26715.

[11] E. Battista, F. Causa, V. Lettera, V. Panzetta, D. Guarnieri, S. Fusco, F. Gentile, P.A. Netti, Ligand engagement on material surfaces is discriminated by cell mechanosensoring, Biomaterials 45 (2015) 72-80, https://doi.org/10.1016/j. biomaterials.2014.12.012.

[12] M. Kato, M. Mrksich, Using model substrates to study the dependence of focal adhesion formation on the affinity of Integrin - Ligand complexes, Biochemistry 43 (2004) 2699-2707, https://doi.org/10.1021/bi0352670.

[13] H. Shin, S. Jo, A.G. Mikos, Biomimetic materials for tissue engineering, Biomaterials 24 (2003) 4353-4364, https://doi.org/10.1016/S0142-9612(03)00339-9.

[14] A.K. Muszanska, E.T.J. Rochford, A. Gruszka, A.A. Bastian, H.J. Busscher, W. Norde, H.C. van der Mei, A. Herrmann, Antiadhesive polymer brush coating functionalized with antimicrobial and RGD peptides to reduce biofilm formation and enhance tissue integration, Biomacromolecules 15 (2014) 2019-2026, https://doi.org/10 1021/bm500168s.

[15] F. Causa, E. Battista, R. Della Moglie, D. Guarnieri, M. Iannone, P.A. Netti, Surface investigation on biomimetic materials to control cell adhesion: the case of RGD conjugation on PCL, Langmuir 26 (2010) 9875-9884, https://doi.org/10.1021/ la100207q.

[16] U. Hersel, C. Dahmen, H. Kessler, RGD modified polymers: biomaterials for stimulated cell adhesion and beyond, Biomaterials 24 (2003) 4385-4415 https://doi. org/10.1016/S0142-9612(03)00343-0.

[17] P.Y.W. Dankers, J.M. Boomker, A. Huizinga-van der Vlag, E. Wisse, W.P.J. Appel, F.M.M. Smedts, M.C. Harmsen, A.W. Bosman, W. Meijer, M.J.A. van Luyn, Bioengineering of living renal membranes consisting of hierarchical, bioactive supramolecular meshes and human tubular cells, Biomaterials 32 (2011) 723-733, https://doi.org/10.1016/j.biomaterials.2010.09.020.

[18] S. Sur, F. Tantakitti, J.B. Matson, S.I. Stupp, Epitope topography controls bioactivity in supramolecular nanofibers, Biomater. Sci. 3 (2015) 520-532, https://doi.org/10 1039/C4BM00326H.

[19] J.H. Collier, Modular self-assembling biomaterials for directing cellular responses, Soft Matter 4 (2008) 2310, https://doi.org/10.1039/b805563g.

[20] O.J.G.M. Goor, S.I.S. Hendrikse, P.Y.W. Dankers, E.W. Meijer, From supramolecular polymers to multi-component biomaterials, Chem. Soc. Rev. 46 (2017) 6621-6637, https://doi.org/10.1039/C7CS00564D.

[21] Q. An, J. Brinkmann, J. Huskens, S. Krabbenborg, J. de Boer, P. Jonkheijm, A supramolecular system for the electrochemically controlled release of cells, Angew. Chem. Int. Ed. 51 (2012) 12233-12237, https://doi.org/10.1002/anie.201205651.

[22] B.B. Mollet, M. Comellas-Aragonès, A.J.H. Spiering, S.H.M. Söntjens, E.W. Meijer, P.Y.W. Dankers, A modular approach to easily processable supramolecular bilayered scaffolds with tailorable properties, J. Mater. Chem. B. 2 (2014) 2483-2493, https://doi.org/10.1039/C3TB21516D.

[23] E. Wisse, A.J.H. Spiering, E.N.M. van Leeuwen, R.A.E. Renken, P.Y.W. Dankers, L.A. Brouwer, M.J.A. van Luyn, M.C. Harmsen, N.A.J.M. Sommerdijk, E.W. Meijer, Molecular recognition in poly( $\varepsilon$-caprolactone)-based thermoplastic elastomers, Biomacromolecules 7 (2006) 3385-3395, https://doi.org/10.1021/bm060688t.

[24] R.A. Koevoets, R.M. Versteegen, H. Kooijman, A.L. Spek, R.P. Sijbesma, E.W. Meijer, Molecular recognition in a thermoplastic elastomer, J. Am. Chem. Soc 127 (2005) 2999-3003, https://doi.org/10.1021/ja0451160.

[25] G.A. Silva, C. Czeisler, K.L. Niece, E. Beniash, D.A. Harrington, J.A. Kessler, S.I. Stupp, Selective differentiation of neural progenitor cells by high-epitope density nanofibers, Science 303 (2004) 1352-1355, https://doi.org/10.1126/science. 1093783

[26] E. Ressouche, S. Pensec, B. Isare, G. Ducouret, L. Bouteiller, Rational design of ureabased two-component Organogelators, ACS Macro Lett. 5 (2016) 244-247, https:// doi.org/10.1021/acsmacrolett.5b00931.

[27] R. Dong, Y. Zhou, X. Huang, X. Zhu, Y. Lu, J. Shen, Functional supramolecular polymers for biomedical applications, Adv. Mater. 27 (2015) 498-526, https://doi. org/10.1002/adma.201402975.

[28] M.J. Webber, E.A. Appel, E.W. Meijer, R. Langer, Supramolecular biomaterials, Nat. Mater. 15 (2016) 13-26, https://doi.org/10.1038/nmat4474.

[29] T.F.A. De Greef, M.M.J. Smulders, M. Wolffs, A.P.H.J. Schenning, R.P. Sijbesma, E.W. Meijer, Supramolecular polymerization, Chem. Rev. 109 (2009) 5687-5754, https://doi.org/10.1021/cr900181u.

[30] D.E.P. Muylaert, G.C. van Almen, H. Talacua, J.O. Fledderus, J. Kluin, S.I.S. Hendrikse, J.L.J. van Dongen, E. Sijbesma, A.W. Bosman, T. Mes, S.H. Thakkar, A.I.P.M. Smits, C.V.C. Bouten, P.Y.W. Dankers, M.C. Verhaar, Early in-situ cellularization of a supramolecular vascular graft is modified by synthetic stromal cell-derived factor-1 $\alpha$ derived peptides, Biomaterials 76 (2016) 187-195, https://doi.org/10.1016/j.biomaterials.2015.10.052.

[31] F.H. Beijer, R.P. Sijbesma, H. Kooijman, A.L. Spek, E.W. Meijer, Strong dimerization of Ureidopyrimidones via quadruple hydrogen bonding, J. Am. Chem. Soc. 120 (1998) 6761-6769, https://doi.org/10.1021/ja974112a.

[32] N.E. Botterhuis, D.J.M. van Beek, G.M.L. van Gemert, A.W. Bosman, R.P. Sijbesma, Self-assembly and morphology of polydimethylsiloxane supramolecular thermoplastic elastomers, J. Polym. Sci. Part A Polym. Chem. 46 (2008) 3877-3885, https://doi.org/10.1002/pola.22680.

[33] H. Kautz, D.J.M. van Beek, R.P. Sijbesma, E.W. Meijer, Cooperative end-to-end and lateral hydrogen-bonding motifs in supramolecular thermoplastic elastomers, Macromolecules 39 (2006) 4265-4267, https://doi.org/10.1021/ma060706z.

[34] W.P.J. Appel, G. Portale, E. Wisse, P.Y.W. Dankers, E.W. Meijer, Aggregation of ureido-pyrimidinone supramolecular thermoplastic elastomers into nanofibers: a kinetic analysis, Macromolecules 44 (2011) 6776-6784, https://doi.org/10.1021/ ma201303s.

[35] G.C. van Almen, H. Talacua, B.D. Ippel, B.B. Mollet, M. Ramaekers, M. Simonet, A.I.P.M. Smits, C.V.C. Bouten, J. Kluin, P.Y.W. Dankers, Development of non-cell adhesive vascular grafts using supramolecular building blocks, Macromol. Biosci. 16 (2016) 350-362, https://doi.org/10.1002/mabi.201500278.

[36] V. Bonito, A.I.P.M. Smits, O.J.G.M. Goor, B.D. Ippel, A. Driessen-Mol, T.J.A.G. Münker, A.W. Bosman, T. Mes, P.Y.W. Dankers, C.V.C. Bouten, Modulation of macrophage phenotype and protein secretion via heparin-IL-4 functionalized supramolecular elastomers, Acta Biomater. 71 (2018) 247-260, https://doi.org/10. 1016/j.actbio.2018.02.032.

[37] S. Spaans, P.P.K.H. Fransen, B.D. Ippel, D.F.A. de Bont, H.M. Keizer, N.A.M. Bax, C.V.C. Bouten, P.Y.W. Dankers, Supramolecular surface functionalization via catechols for the improvement of cell-material interactions, Biomater. Sci. 5 (2017) 1541-1548, https://doi.org/10.1039/C7BM00407A.

[38] D.J.M. van Beek, A.J.H. Spiering, G.W.M. Peters, K. te Nijenhuis, R.P. Sijbesma, Unidirectional dimerization and stacking of Ureidopyrimidinone end groups in polycaprolactone supramolecular polymers, Macromolecules 40 (2007) 8464-8475, https://doi.org/10.1021/ma0712394.

[39] O.J.G.M. Goor, H.M. Keizer, A.L. Bruinen, M.G.J. Schmitz, R.M. Versteegen, H.M. Janssen, R.M.A. Heeren, P.Y.W. Dankers, Efficient functionalization of additives at supramolecular material surfaces, Adv. Mater. 29 (2017) 1604652, 
https://doi.org/10.1002/adma.201604652.

[40] N.E. Botterhuis, S. Karthikeyan, A.J.H. Spiering, R.P. Sijbesma, Self-sorting of guests and hard blocks in bisurea-based thermoplastic elastomers, Macromolecules 43 (2010) 745-751, https://doi.org/10.1021/ma902585w.

[41] J. Courtois, I. Baroudi, N. Nouvel, E. Degrandi, S. Pensec, G. Ducouret, C. Chanéac, L. Bouteiller, C. Creton, Supramolecular soft adhesive materials, Adv. Funct. Mater. 20 (2010) 1803-1811, https://doi.org/10.1002/adfm.200901903.

[42] E. Wisse, L.E. Govaert, H.E.H. Meijer, E.W. Meijer, Unusual tuning of mechanical properties of thermoplastic elastomers using supramolecular fillers, Macromolecules 39 (2006) 7425-7432, https://doi.org/10.1021/ma060986i.

[43] N.E. Botterhuis, S. Karthikeyan, D. Veldman, S.C.J. Meskers, R.P. Sijbesma, Molecular recognition in bisurea thermoplastic elastomers studied with pyrenebased fluorescent probes and atomic force microscopy, Chem. Commun. (2008) 3915, https://doi.org/10.1039/b804457k.

[44] B.D. Ippel, H.M. Keizer, P.Y.W. Dankers, Supramolecular antifouling additives for robust and efficient functionalization of elastomeric materials: molecular design matters, Adv. Funct. Mater. 29 (2019) 1805375, , https://doi.org/10.1002/adfm. 201805375.

[45] M. Hutin, E. Burakowska-Meise, W.P.J. Appel, P.Y.W. Dankers, E.W. Meijer, From molecular structure to macromolecular organization: keys to design supramolecular biomaterials, Macromolecules 46 (2013) 8528-8537, https://doi.org/10.1021/ ma401552e.

[46] I. de Feijter, O.J.G.M. Goor, S.I.S. Hendrikse, M. Comellas-Aragonès, S.H.M. Söntjens, S. Zaccaria, P.-P.K.H. Fransen, J.W. Peeters, L.-G. Milroy, P.Y.W. Dankers, Solid-phase-based synthesis of Ureidopyrimidinone-peptide conjugates- for supramolecular biomaterials, Synlett 26 (2015) 2707-2713, https:// doi.org/10.1055/s-0035-1560520.

[47] A.T. Nguyen, S.R. Sathe, E.K.F. Yim, From nano to micro: topographical scale and its impact on cell adhesion, morphology and contact guidance, J. Phys. Condens. Matter 28 (2016) 183001, , https://doi.org/10.1088/0953-8984/28/18/183001.

[48] A.S. Yap, K. Duszyc, V. Viasnoff, Mechanosensing and mechanotransduction at cell-cell junctions, Cold Spring Harb. Perspect. Biol. 10 (2018) a028761, , https:// doi.org/10.1101/cshperspect.a028761.
[49] S. Marlar, S.A. Abdellatef, J. Nakanishi, Reduced adhesive ligand density in engineered extracellular matrices induces an epithelial-mesenchymal-like transition, Acta Biomater. 39 (2016) 106-113, https://doi.org/10.1016/j.actbio.2016.05.006.

[50] D.H. Kim, D. Wirtz, Focal adhesion size uniquely predicts cell migration, FASEB J. 27 (2013) 1351-1361, https://doi.org/10.1096/fj.12-220160.

[51] J.H. Beer, K.T. Springer, B.S. Coller, Immobilized Arg-Gly-Asp (RGD) peptides of varying lengths as structural probes of the platelet glycoprotein IIb/IIIa receptor, Blood 79 (1992) 117-128 http://www.ncbi.nlm.nih.gov/pubmed/1728303.

[52] M.J. Wilson, S.J. Liliensiek, C.J. Murphy, W.L. Murphy, P.F. Nealey, Hydrogels with well-defined peptide-hydrogel spacing and concentration: impact on epithelial cell behavior, Soft Matter 8 (2012) 390-398, https://doi.org/10.1039/C1SM06589K.

[53] S.J. Attwood, E. Cortes, A.W.M. Haining, B. Robinson, D. Li, J. Gautrot, A. del Río Hernández, Adhesive ligand tether length affects the size and length of focal adhesions and influences cell spreading and attachment, Sci. Rep. 6 (2016) 34334, https://doi.org/10.1038/srep34334.

[54] H. Kang, H.J. Jung, D.S.H. Wong, S.K. Kim, S. Lin, K.F. Chan, L. Zhang, G. Li, V.P. Dravid, L. Bian, Remote control of heterodimeric magnetic nanoswitch regulates the adhesion and differentiation of stem cells, J. Am. Chem. Soc. 140 (2018) 5909-5913, https://doi.org/10.1021/jacs.8b03001.

[55] A. Beaugendre, S. Degoutin, S. Bellayer, C. Pierlot, S. Duquesne, M. Casetta, M. Jimenez, Self-stratifying coatings: a review, Prog. Org. Coat. 110 (2017) 210-241, https://doi.org/10.1016/j.porgcoat.2017.03.011.

[56] R.C. van Gaal, M. Fedecostante, P.-P.K.H. Fransen, R. Masereeuw, P.Y.W. Dankers, Renal epithelial monolayer formation on monomeric and polymeric catechol functionalized supramolecular biomaterials, Macromol. Biosci. 19 (2019) 1800300 , , https://doi.org/10.1002/mabi.201800300.

[57] A.B.C. Buskermolen, N.A. Kurniawan, C.V.C. Bouten, An automated quantitative analysis of cell, nucleus and focal adhesion morphology, PLoS One 13 (2018) e0195201, , https://doi.org/10.1371/journal.pone.0195201.

[58] X. Dai, Z. Su, J.O. Liu, An improved synthesis of a selective $\alpha v \beta 3$-integrin antagonist cyclo(-RGDfK-), Tetrahedron Lett. 41 (2000) 6295-6298, https://doi.org/ 10.1016/S0040-4039(00)01060-1. 